\title{
ESTETIKA TARI KUDA KEPANG DESA PENIRON KABUPATEN KEBUMEN
}

\author{
Esti kurniawati \\ Indriyanto, Veronica Eny Iryanti \\ Universitas Negeri Semarang \\ Kampus Sekaran Gunungpati, Semarang 50229, Indonesia \\ Email: estykurnia99@gmail.com \\ indriyanto609@gmail.com
}

\begin{abstract}
Abstrak
Tari Kuda Kepang Desa Peniron Kabupaten Kebumen merupakan tari kerakyatan yang tumbuh dan tetap ada di desa peniron kecamatan Pejagoan Kabupeten Kebumen. Tari Kuda kepang desa Peniron memiliki nilai keindahan yang dapat dilihat dari aspek wujud, isi dan penampilan. Kajian pokok wujud yaitu aspek pertunjukan, isi yaitu suasana, gagasan, pesan ; penampilan yaitu bakat, ketrampilan, sarana. Tujuan dari penelitian ini yaitu mengetahui nilai keindahan yang terdapat pada Tari Kuda Kepang Desa Peniron. Metode yang digunakan adalah metode deskripsi kualitatif. Lokasi penelitian dilakukan di paguyuban Purwo Budoyo desa Peniron dan di tempat pementasan Tari kuda Kepang di Desa Peniron. Peneitian menggunakan teknik observasi, wawancara dan dokumentasi. Hasil penelitian nilai keindahan Kuda Kepang Desa Peniron terlihat pada pola pertunjukan yang terdiri dari bagian awal (babak pertama), bagian inti (babak kedua), bagian akhir (babak ketiga). Bentuk pertunjukan Tari Kuda Kepang Desa peniron terdiri dari gerak, iringan, tata rias, tata lampu/suara, dan tempat pentas yang memberi kesan indah, dinamis, gagah dan kuat.
\end{abstract}

Kata Kunci : Bentuk Pertunjukan, Estetika, Tari Kuda Kepang

\section{PENDAHULUAN}

Karya seni akan menjadi indah apabila memiliki beberapa unsur-unsur keindahan dalam seni yang dapat dilihat dari wujud, bentuk atau rupa. Unsur lain yang berperan menimbulkan rasa indah pada pengamat yaitu, keutuhan atau kebersatuan ( unity), penonjolan atau penekanan (dominance) , dan keseimbangan (balance).

Unsur keindahan dalam seni tari dapat dilihat memalui gerak dan proses koreografinya. keindahan juga dapat dilihat melalui elemen-elemen dan isi nya yang meliputi ide, gagasan, suasana, ibarat atau pesan.

Daerah kebumen memiliki berbagai kesenian tradisional yang sudah lama tumbuh dan berkembang dalam kehidupan masyarakat salah satunya adalah kesenian kuda kepang atau masyarakat kebumen sering menyebutnya dengan nama Tari Kuda Kepang. Kesenian kuda kepang merupakan salah satu contoh kesenian dalam bidang tari tradisional. Menurut ( 
Jazuli 1994 : 70 ) Tari tradisional adalah tari yang lahir, tumbuh, berkembang dalam suatu masyarakat yang kemudian diturunkan atau diwariskan secara terus menerus dari generasi ke generasi.

Tari Kuda Kepang ini memiliki keindahan tersendiri jika dimaikan secara rampak dan kompak karena tarian ini merupakan tarian kelompok. Keindahan tarian kuda kepang juga bisa dilihat dari kelincahan penari dalam melakukan gerak-gerak tari. Nilai keindahahan lainnya juga bisa dilihat dari tata rias dan busana yang dikenakan oleh para penari. Tata rias dan busana yang digunakan masih tergolong sederhana namun, tidak menutup nilai keindahan pada tarian kuda kepang "Puspo Budoyo" ini. Alat musik yang digunakan masih sederhana namun menurut bapak Suwarno selaku ketua paguyuban kesenian ini, musik tersebutlah yang menarik perhatian penonton untuk menonton pertunjukan tersebut.

Terdapat beberapa pokok masalah yang dapat dikaji pada penelitian tentang bagaimana Estetika Tari Kuda Kepang Desa Peniron Kabupaten Kebumen, dengan kajian pokok :

Bagaimana bentuk pertunjukan Tari Kuda Kepang "Purwo Budoyo" di desa Peniron Kecamatan Pejagoan Kabupanten Kebumen. Bagaimana isi yang terkandung dalam Tari Kuda kepang "Purwo Budoyo" di desa Peniron Kecamatan Pejagoan Kabupaten Kebumen. Bagaimana penampilan Tari Kuda kepang "Purwo Budoyo" di desa Peniron Kecamatan Pejagoan Kabupaten Kebumen.

Tujuan penelitian ini adalah untuk mengetahui bagaimana bentuk pertunjukan Tari Kuda Kepang "Purwo Budoyo" desa Peniron Kabupaten Kebumen. Mengetahui nilai estetis yang terdapat dalam Tari Kuda Kepang "Purwo Budoyo" desa Peniron Kabupaten Kebumen yang meliputi bentuk, isi dan penampilan.
Ilmu estetika adalah ilmu yang mempelajari segala sesuatu yang berkaitan dengan keindahan, mempelajari semua aspek dari apa yang kita sebut keindahan (Djelantik 1999 : 9). bagi orang yang menikmatinya. Wujud meliputi bentuk atau unsur yang mendasar dan struktur. Isi atau bobot mempunyai tiga aspek yaitu suasana, gagasan, dan pesan. Sedangkan penampilan kesenian memiliki tiga unsur yang berperan yaitu bakat, keterampilan, adan sarana atau media.

Banyak hal lain dalam kesenian yang tidak nampak dengan mata seperti misalnya suara gamelan, nyanyian, yang tidak mempunyai rupa, tetapi jelas mempunyai wujud. Baik wujud yang nampak dengan mata (visual) maupun wujud yang nampak melalui telinga(akustis) bisa diteliti dengan analisa, dibahas tentang komponenkomponen yang menyusunnya, serta dari segi susunannya itu sendiri. Semua wujud terdiri dari bentuk (form) dan struktur atau tatanan (structure).

Bentuk yang nampak melalui mata misalnya seperti gerak (struktur: tenaga, ruang dan waktu), tata rias (wajah dan busana), tempat pentas, dan tata lampu/tata suara.

Bobot dari suatu karya seni maksudnya adalah isi atau makna dari apa yang disajikan pada pengamat. Bobot karya seni dapat ditangkap secara langsung dengan panca indra seperti misalnya kita melihat lukisan yang menggambarkan orang-orang belanja di pasar ( Djelantik 1999 : 59-60 ). Secara umum bobot dalam kesenian dapat dinikmati setidak-tidaknya pada 3 hal yaitu suasana, gagasab/ide, ibarat/pesan.

Menurut (Murgiyanto 1983 : 107) pemanggungan atmosferis adalah pengaturan panggung yang dilakukan untuk menciptakan suasana yang menunjang tarian yang dipertunjukan. Untuk menciptakan suasana pagi, sore atau malam hari misalnya sering dilakukan dengan pengaturan cahaya 
secara cermat. Untuk menciptakan suasana tertentu, acapkali pula dilakukan dengan meleraikan benda-benda yang dapat memberikan sugesti tempat yang dimaksud.

Suasana dapat dapat tercapai dengan adanya tata cahaya, musik iringan tari dan tempat pentas tari. Suasana gembira akan terasa jika musik yang digunakan juga menimbulkan rasa gembira, tata cahaya yang digunakan juga sesuai yaitu lampu general dan kuning untuk menggambarkan suasana gembira, sedangkan tempat pentas atau panggung yang digunakan diberi bendabenda yang menunjang suasana tersebut.

Dalam pertunjukan tari ide/gagasan dijadikan pedoman dalam pembuatan karya tari tersebut. Baik buruknya sebuah karya juga dipengaruhi oleh adanya gagasan atau ide itu sendiri. Menurut (Widyastutieningrum 2014 : 65-66) gagasan isi merupakan objek yang akan digarap bisa berupa nilai moral, seperti kepahlawanan, pengalaman jiwa, etika, kritik dan sebagainya. Dalam koreografi atau susunan tari akan terlihat dua hal yaitu bentuk dan isi.

Pesan merupakan sesuatu hal yang disampaikan melalui lisan, tindakan atau perbuatan. Dalam sebuah pertunjukan tari pesan ditunjukan melalui gerak yang ditampilkan dalam sebuah pertunjukan. Menurut (Sujarno 2013 : 47) dalam setiap pementasannya, beberapa bentuk kesenian tradisional selalu membawakan sebuah misi yang ingin disampaikan kepada para penonton atau para pendengarnya. Dengan demikian, sebuah seni pertunjukan, kesenian tradisional selalu melihat atau menampilkan pesan atau nilai-nilai yang sesuai pada masanya. Apakah itu pesanpesan yang bernilai sosial, politik, moral da sebagainya.

Selain aspek wujud dan bobot, penampilan merupakan salah satu bagian mendasar yang dimiliki semua benda seni atau peristiwa kesenian.
Dengan penampilan dimaksudkan cara penyajian, bagaiman kesenian itu disuguhkan kepada yang menyaksikannya, penonton, para pengamat, pembaca, pendengar, khalayak ramai pada umumnya. Tiga unsur yang berperan dalam penampilan adalah bakat, ketrampilan, sarana atau media

Ketrampilan adalah kemahiran dalam pelaksanaan sesuatu yang dicapai dengan latihan. Taraf kemahiran tergantung dari cara melatih dan ketekunannya melatih diri. Cara melatih tidak kurang pentingnya dari pada ketekunan.

Sarana atau media yang diperlukan pada pertunjukan tari sangat berpengaruh daalam kelangsungan dan kualitas pertunjukan. Menurut (Djelantik 1999 :78)

\section{METODE}

Pada penelitian yang mengkaji tentang Estetika Tari Kuda Kepang ini menggunakan metode penelitian kualitatif, sehingga data yang dikaji berupa data deskriptif. Dalam penelitian kualitatif peneliti harus memperoleh data secara langsung pada narasumber. Peneliti harus mengenali atau mengetahui terlebih dahulu siapa narasumber yang akan memberikan data atau informasi.

Pendekatan yang digunakan yaitu pendekatan etik dan emik. Pendekatan etik dan emik pada dasarnya merefer pada sudut pandang penelitian budaya itu sendiri. jika penelitian berdasarkan pada sudut pandang partisipan (informan setempat) berati menggunakan emik dan bila menggunakan sudut pandang observer (peneliti) berati menggunakan etik. (Endaswara 2012 : 34-35). Menurut Endaswara (2012:36) jika pendekatan etik dan emik diperbandingkan keduanya akan tampak karakteristik yang jelas.

Penelitian ini dilakukan di desa Peniron Kecamatan Pejagoan Kabupaten 
Kebumen. Teknik pengumpulan data yaitu menggunakan teknik observasi, wawancara, dan dokumentasi.

Observasi adalah suatu penyelidikan secara sistematis menggunakan kemampuan indera manusia. Observasi juga dibantu dengan foto dan tape recorder. Observasi yang dilakukan peneliti secara langsung terhadap objek dengan cara mengamati langsug objek yang akan diteliti. Observasi penelitian awal yaitu peneliti melakukan survey lokasi penelitian

Wawancara adalah suatu teknik yang digunakan untuk memperoleh informasi tentang kejadian yang oleh peneliti tidak dapat diamati sendiri secara langsung, baik karena tindakan atau peristiwa yang terjadi dimasa lampau ataupun karena peneliti tidak diperbolehkan hadir ditempat kejadian itu (Rohendi 2011 : 208).

Metode dokumentasi yaitu mencari data mengenai hal-hal atau variabel yang berupa catatan, transkrip, buku, surat kabar, majalah, prasasti, notulen rapat, lengger, agenda, dan sebagainya (Suharsimi $2010: 274$ ).

Dokumen merupakan cacatan peristiwa yang sudah berlalu. Dokumen bisa berbentuk tulisan, gambar atau karya-karya monumental dari seseorang. Dokumen yang berbentuk tulisan misalnya catatan harian, sejarah kehidupan, ceritera, biografi. Dokumen yang berbentuk gambar misalnya foto, gambar hidup, sketsa dan lain-lain. (Sugiyono 2012 : 240).

Analisis merupakan suatu kegiatan reflektif, bertujuan untuk bergerak dari data ke tahapan konseptual. Dalam kegiatan analisis, data senantiasa perlu dikategorisasikan baik dalam kaitannya dengan beberapa sistem yang disusun. (Rohendi 2011 : 231). Jannet Adshead dkk dalam (Murgiyanto 2002 : 9) membagi proses analisa tari kedalam empat tahap sebagai berikut :
Mengenali dan mendeskripsikan komponen-komponen pertunjukan tari seperti gerak, penari, aspek visual, dan elemen-elemen auditif (1). Memahami hubungan antara komponen pertunjukan dalam perjalanan ruang dan waktu, bentuk dan struktur koreografi (2). Melakukan interpretasi berdasarkan konsep dan dan latar belakang sosial, budaya, konteks pertunjukan, gaya dan genre, tema/isi tarian, dan konsep interpretasi spesifik (3). Melakukan evaluasi berdasarkan : nilai-nilai yang berlaku didalam kebudayaan dan masyarakat pendukung tarian (4).

\section{HASIL DAN PEMBAHASAN}

\section{Bentuk Pertunjukan Tari kuda Kepang Desa Peniron}

Bentuk pertunjukan tari Kuda Kepang dapat dilihat melalui pola pertunjukan dan elemen-elemen pertunjukannya.

\section{Pola Pertunjukan Tari Kuda Kepang Desa Peniron}

Pertunjukan tari Kuda Kepang memiliki 3 pola bagian yaitu bagian awal pertunjukan, bagian inti pertunjukan dan bagian akhir pertunjukan. Bagian awal pertunjukan merupakan bagian pembuka yang diawali dengan masuknya penari. Bagian inti pertunjukan yaitu bagian jogedan inti yang dilakukan penari. Bagian akhir yaitu bagian ndemdeman atau kesurupan.

\section{Elemen Pertunjukan Tari}

Sebuah pertunjukan tarian terdapat unsur-unsur pendukung yang mendukung jalannya pementasan. Pada pementasan Tari Kuda Kepang di Desa Peniron juga terdapat unsur-unsur pendukung yaitu unsur gerak, tata raias dan busana, iringan, properti dan tempat pentas atau area pentas.

\section{Gerak}

Ragam gerak dalam tari Kuda Kepang Desa Peniron yaitu : Sembahan, Jalan muter, Hormat, Gerak 
penghubung/, selut ,Lembehan, Jalan gejug mundur, Jalan jinjit, Jalan gejug maju, Entragan, Perang, Laku, Manggut, Nggawa Sampur, Langkah manggut, Laku bebas, Adu, gedeg, Jingkrak, Maju mundur, Langkah amba, Seleh kuda kepang, Mendem / ndadi. Ragam gerak dilakukan oleh beberapa elemen bagianbagian tubuh penari yaitu kepala, tangan, kaki, dan badan. Kesan keindahan yang ditimbulkan dari bentuk gerak adalah kuat dan gagah yang ditimbulkan dari aksen-aksen gerak yang kuat, tempo yang cepat, dan volume gerak yang lebar.

\section{Iringan}

Pada tari, fungsi musik dapat dikelompokan menjadi 3 yaitu, sebagai pengiring tari, sebagai pemberi suasana, sebagai ilustrasi tari. Alat musik pengiring yang digunakan dalam Tari Kuda Kepang desa Peniron Kabupaten Kebumen berupa gamelan yang masih tradisional diantaranya : Saron,Kendang , Gong bumbung, Gong 3 gantung.

Pada musik pengiring terdapat instrumen musik atau musik gending tanpa suara vocal (sinden) musik tersebut sebagai musik aba-aba atau musik persiapan penari sebelum menari. Musik instrumen tidak hanya berada pada awal pembuka namun terkadang berada ditengah atau diakhir pertunjukan. Peran atau fungsi lain musik instrumen yaitu sebagai pengatur suasana, tempo dan dinamika musik. Tempo pada musik pengiring tari kuda kepang desa peniron cenderung sedang namun, pada adegan tertentu tempo yang digunakan pelan dan cepat.

\section{Tata Rias dan Busana}

Tari Kuda Kepang di desa Peniron merupkan tari kerakyatan sehingga, tata rias yang digunakan masih sederhana. Tata rias yang digunakan dalam pertunjukan Tari Kuda Kepang adalah rias korektif dengan mempertajam bagian mata, alis dan bibir sehingga terlihat lebih gagah. Penggunaan garis pada dagu juga memberi kesan lebih gagah pada penari.

Tata busana merupakan unsur pendukung dalam sebuah pertunjukan. Tata busana termasuk unsur yang penting untuk memperkuat karakter tokoh dan juga menambah nilai estetis pada suatu pertunjukan atau pementasan tari.

Tari Kuda Kepang di desa Peniron menggunakan tata busana yang menggambarkan prajurit yang akan berperang. Tata busana yang digunakan diantaranya baju, celana, jarik, iket, slendang atau sampur, stagen/korset, songkok/jamang, sumping dan kace. Keunikan busana/ kostum yang diguanakan penari terletak pada jamang/songkok. Penggunaan kaca mata hitam juga bertujuan agar penari terlihat lebih gagah.

\section{Tempat Pentas}

Suatu pertunjukan apapun selalu memerlukan tempat untuk pementasan pertunjukan tersebut. Tari Kuda Kepang Desa Peniron merupakan tari kerakyatan yang berbentuk tari kelompok sehingga memerlukan tempat yang cukup luas. Biasanya tempat yang digunakan adalah lapangan atau halaman rumah penduduk tergantung acara dalam pementasan tersebut dipentaskan. Pertunjukan dilakukan dilapangan atau tempat yang luas agar para penari lebih leluasa dalam menari.

\section{Properti}

Properti merupakan unsur pendukung yang memiliki peranan tersendiri dalam sebuah pertunjukan tari. Properti yaitu peralatan yang berkaitan dan mendukung tarian yang disajikan. Selain itu, properti juga memiliki daya tarik tersendiri bagi penonton yang menyaksikan pertunjukan. Penggunaan properti pada sebuah tarian menimbulkan kesan lebih menarik untuk dilihat. 
Properti yang digunakan dalam Tari Kuda Kepang Desa Peniron adalah kuda kepang dan pedang atau mereka lebih sering menyebutnya bendo.

Hiasan menyerupai bendera melambangkan rasa nasionalisme terhadap negara Indonesia. Pedang yang digunakan untuk berperang menggunakan pedang yang sudah tidak tajam agar tidak membahayakan penari kuda kepang. Pedang yang digunakan untuk memperkuat karakter dan sebagai properti saat melakukan perang.

\section{Pelaku}

Pelaku diperlukan dalam setiap pertunjukan tarian. Pada pertunjukan tari kuda kepang pelaku seni atau orang yang terlibat dalam pementasan yaitu penari, penimbun atau pawang dan pemusik. Ketiga pelaku tersebut memiliki peran penting dalam pertunjukan tari kuda kepang. Penari kuda kepang boleh laki-laki ataupun perempuan karena tidak ada aturan jenis kelamin khusus dalam menarikan tarian kuda kepang.

\section{Suasana}

Suasana yang tergambar dalam tarian meliputi suasana gembira dan suasana tegang. Suasana gembira pada saat jogetan bersama sedangkan pada saat perang dan mendeman berubah suasana menjadi tegang. Pada saat suasana gembira volume gerak penari cenderung sedang. Pada saat suasana sedih volume gerak yang digunakan lemah. Suasana juga didukung oleh musik atau iringan tari kuda kepang. Tempo yang digunakan pada saat suasana gembira cenderung lebih cepat begitu juga pada saat suasana tegang tempo akan lebih cepat lagi.

\section{Ide atau Gagasan}

Tari Kuda Kepang Peniron merupakan Tari kerakyatan yang sudah ada dari jaman dahulu. Tarian diambil dari kisah prajurit perang Indonesia melawan Belanda. Generasi pertama Tari kuda kepang Desa Peniron adalah
Mbah Kerta Sentana yang kemudian diturunkan kepada Parta Wijaya dan kemudian diturunkan ke anak cucu mereka hingga bapak Suarno (wawancara tanggal 18 Mei 2016) . Tari kuda kepang menggambarkan prajurit perang yang terdiri dari dua kelompok barisan perang.

\section{Pesan}

Pada sebuah pertunjukan tari pasti memiliki pesan yang disampaikan kepada penikmat tari. Pesan yang dapat diambil dalam Tari Kuda Kepang Desa Peniron terlihat dari adegan-adegan dan ragam gerak yang terdapat pada Tari Kuda Kepang Desa peniron. Pesan bagi penonton yaitu pesan ekspresif penari yang menggambarkan prajurit perang yang sedang berperang menaiki kuda kepang. Pesan lain yang dapat diambil yaitu prajurit perang harus memiliki keberanian.

\section{Penampilan}

Penampilan pada pertunjukan Tari Kuda Kepang Desa Peniron dipengaruhi oleh bakat, teknik dan sarana. Bakat yang dimiliki oleh setiap pemain mempengaruhi luwes atau tidaknya dalam menari. Pada dasarnya beberapa penari Kuda Kepang Desa Peniron tidak harus memiliki bakat dalam menari karena menurut bapak Dulaisan, siapapun boleh menjadi anggota paguyuban dan berlatih menari.

\section{KESIMPULAN}

Simpulan berdasarkan hasil penelitian Estetika Tari Kuda Kepang Desa Peniron Kabupaten Kebumen adalah bentuk pertunjukan tari Kuda Kepang terdiri dari pola dan elemen pertunjukan Pertunjukan tari Kuda Kepang memiliki 3 pola bagian yaitu bagian awal pertunjukan, bagian inti pertunjukan dan bagian akhir pertunjukan. Bagian awal pertunjukan merupakan bagian pembuka yang diawali dengan masuknya penari. Bagian inti pertunjukan yaitu bagian jogedan inti yang dilakukan penari. Bagian akhir yaitu bagian ndemdeman 
atau kesurupan. Estetika Tari Kuda Kepang Desa Peniron Kabupaten Kebumen meliputi aspek wujud, bobot/isi, dan penampilan. Aspek wujud terdiri dari gerak, iringan, tata rias, tempat pentas, dan pelaku yang memberi kesan kuat dan gagah. Aspek isi meliputi ide atau gagasan, pesan, dan suasana. Aspek penampilan terdiri dari bakat, keterampilan, dan sarana atau media yang memberi kesan sederhana.

\section{REFERENCES}

Ambarwangi, S., \& Suharto, S. (2014). REOG AS MEANS OF STUDENTS' APPRECIATION AND CREATION IN ARTS AND CULTURE BASED ON THE LOCAL WISDOM. Harmonia: Journal Of Arts Research And Education, 14(1), 37-45.

doi:http://dx.doi.org/10.15294/har monia.v14i1.2789

Ambarwangi, S., \& Suharto, S. (2013). PENDIDIKAN

MULTIKULTURAL

DI

SEKOLAH MELALUI

PENDIDIKAN SENI TRADISI.

Harmonia: Journal Of Arts Research And Education, 13(1). doi:http://dx.doi.org/10.15294/har monia.v13i1.2535

Lestari, P. (2014). MAKNA SIMBOLIK SENI BEGALAN BAGI PENDIDIKAN ETIKA MASYARAKAT. Harmonia: Journal Of Arts Research And Education, 13(2). doi:http://dx.doi.org/10.15294/har monia.v13i2.2782

Arikunto, Suharsimi. 2010. Prosedur Penelitian. Jakarta : Rineka Cipta.

Djelantik. 1999. Estetika sebuah Pengantar. Bandung : Masyarakat Seni Pertunjukan Indonesia.
Endraswara, Suwardi. 2012. Metodologi Penelitian Budaya. Yogyakarta : Gajah Mada University Press.

Jazuli, Muhamad. 1994. Telaah Teoretis Tari. Semarang. IKIP Semarang Press.

Murgiyanto, Sal. 2002. Kritik Tari. Jakarta : Masyarakat Seni Indonesia.

1983. Koreografi Pengetahuan Dasar Komposisi Tari. Surakarta : Departemen Pendidikan dan Kebudayaan.

Rohidi, Tjetjep Rohendi. 2011. Metodelogi Penelitian Seni. semarang : Cipta Prima Nusantara.

Sugiyono. 2012. Metode Penelitian Kualitatif Kuantitatif dan $R \& D$. Bandung : ALFABETA

Sujarno dkk. 2013. Seni Pertunjukan Tradisional, Nilai, Fungsi, dan Tantangannya. Yogyakarta : Kementrian Kebudayaan dan Pariwisata

Putra, B. (2013). PENGEMBANGAN MODEL KONSERVASI KESENIAN LOKAL SEBAGAI KEMASAN SENI WISATA DI KABUPATEN SEMARANG. Harmonia: Journal Of Arts Research And Education, 12(2). doi:http://dx.doi.org/10.15294/har monia.v12i2.2525

$\begin{array}{lr}\text { Wiyoso, J. (2013). MOTIVASI } \\ \text { MASUKNYA } & \text { CAMPURSARI } \\ \text { KE DALAM PERTUNJUKAN } \\ \text { JARAN KEPANG. Harmonia: } \\ \text { Journal Of Arts Research And } \\ \text { Education, } \\ \text { doi:http://dx.doi.org/10.15294/har } \\ \text { monia.v12i1.2217 }\end{array}$

Widyastutieningrum, Sri Rochana dkk. Pengantar Koreografi. Surakarta : ISIS press Surakarta. 
Maryono, -. (2011). REOG KEMASAN SEBAG AIASET PARIWISATA UNGGULAN KABUPATEN PONOROGO (The Packes Reog as the high tourism ofPonorogo residence). Harmonia: Journal Of Arts Research And Education, $8(2)$.

doi:http://dx.doi.org/10.15294/har monia.v8i2.788 